\title{
ISCHAEMIC STROKES
}

\author{
Geoffrey C. KNIGHT, F.R.C.S. \\ Surgeon in Charge, Regional Neurosurgical Unit. Brook Hospital, S.E.18; Neurosurgeon, British Postgraduate \\ Medical School; Hon. Senior Surgeon, West End Hospital for Neurology and Neurosurgery \\ Simon Behrman, M.R.C.P.(Lond.), B.Sc.(Hon.)(Lond.) \\ Consultant Neurologist, Regional Neurosurgical Unit, Brook Hospital, S.E.18; Consultant Physician, \\ Moorfields Eye Hospital
}

By 'strokes' we understand the sudden disorders of function of the central nervous system, due to closure or rupture of a blood vessel contributing to the cerebral circulation. We shall confine ourselves to a brief consideration of some of the effects of occlusive disease of these vessels.

The discovery that there was a close relationship between strokes and hæmorrhage in the cerebral hemisphere, on the side contralateral to the hemiplegia, is comparatively recent, and dates from the 17 th century. This discovery greatly influenced medical thought throughout the 18 th century, since cerebral hæmorrhage became synonymous with strokes and apoplexy. The alternative ischæmic causation of strokes became gradually recognized only in the 19th century and Robert Graves was certainly not aware of this pathogenesis of apoplexy when writing his 'Clinical Medicine' in 1843 .

\begin{abstract}
‘... To quote one of many examples I myself have seen: a man named Thomas Lynch was admitted into Sir Patrick Dun's Hospital, afflicted with symptoms indicative of cerebral disease. During his residence in the hospital he suffered four or five attacks of hemiplegia, in every respect complete, and depriving him of the use of his speech. Some of these attacks lasted only fifteen minutes, while the longest continued about an hour and a half; they ceased as suddenly as they commenced, and left no traces of hemiplegia behind them. The circumstances of this case evidently prevent us from assigning each attack to a separate effusion of blood: for were it owing to this cause, it would be impossible to account at once for the sudden appearance and sudden cessation of so extensive and complete a paralysis. Let it not be imagined, however, that I wish to throw doubts upon the beneficial influence of morbid anatomy on the diagnosis and treatment of diseases of the brain-my object in making these observations is not to retard, but to advance, the progress of morbid anatomy by pointing out errors of some generally received opinions' (Graves, I 884).
\end{abstract}

Robert Graves further contended that 'patients could be rendered for the time more or less com-

A paper read to a Conference of Physicians of the South East Metropolitan Region at the Brook Hospital, March 17, 1962. pletely hemiplegic, and yet recover in the cours of a few minutes or hours the use of the affecte side so suddenly and so perfectly, as to precluce the idea of local lesion, such as could be detected by the scalpel of the anatomist'. This conceptio of sudden recurrent reversible abolition of cerebrab function without any demonstrable changes the nerve tissue has received a good deal of attention in the medical literature since then. William Russell attributed the 'intermittent cloई ing of cerebral arteries' to their 'abnormal irritability' (Russell, I909). A case described by Oslë seemed to reinforce the cerebral 'vasospasnas theory. This was an individual presenting simalat recurrent paralytic attacks, and who in addifo was subject to vessel spasm in the extremities due to Raynaud's disease (Osler, 19II). It was surgeon, Howard C. Naffziger (Fleming and Naffziger, 1927), who was first to criticize this explanation. He had noted 'great thickening and hardening of the vessels' in patients with intermittent strokes and he suggested that the latter could 'best be explained by a fall of the generay blood pressure, below the patient's optimum without the necessity of presuming a questionable vessel spasm. Many causes may be operative $i$ bringing about the lowering of blood pressure Myocardial weakness may precede faults of cerebral circulation as well as elsewhere'. The next important milestone in our better under standing of strokes was the publication of the paper by Hicks and Warren in 1951. They had studied 100 brains with apoplectic infarctions, the lesions of which were sufficiently large to permis a careful study. In 60 brains no 'mechanic occlusion' of the cerebral vessels could be demong strated, i.e. all the cerebral vessels were patenf In a somewhat similar but smaller series Yat and Hutchinson (196r) found 'no significarart stenosis or occlusion of intracranial arteries' itw $46 \%$ of their cases with cerebral infarction. The explanation for this observation was soon pros vided by the results of carotid angiography whicl 
following the introduction of the percutaneous technique, was being performed with increasing frequency. Many unsuspected cases of carotid occlusion were thus being revealed, and the extracranial arteries contributing to the formation of the circle of Willis were subjected to greater scrutiny. The outcome of these studies, which are still in progress, is that atheromatous stenosis of carotid and vertebral arteries is relatively common in individuals above the age of 50 . In a consecutive study of $\mathrm{I}, \mathrm{I} 75$ cases, severe atherosclerosis of the circle of Willis and of the arteries contributing to it, was found in close on $50 \%$ of individuals above the age of 50 (Baker and Iannone, 1961). A somewhat similar study of I00 unselected autopsies of bodies over the age of 50 showed occlusion of at least one artery supplying the brain in $11 \%$ (Martin, Whisnant and Sayre, I960). So great is the functional efficiency of the circle of Willis that not only may individuals with even bilateral carotid occlusion remain symptom-free, but they may show a normal basal cerebral blood flow, which can be augmented to a normal extent by inhalation of $5 \%$ carbon dioxide and $95 \%$ oxygen (Fazekas, Yaan, Gallow, Paul and Alman, I962).

As we have seen, in the study of strokes the pathologist's purview has gradually extended so as to include not only the cranial and extracranial arteries but also the aorta within the range of his examination (Yates and Hutchinson, 196r). These studies reveal that in a good many individuals over the age of 50 the blood-carrying capacity of the cerebral vessels, and of the main arteries conveying blood to the cerebrum, can be greatly reduced without the causation of 'strokes'.

Thus it can be concluded that only a small proportion of the individuals with severe atheromatous stenosis of these vessels develop strokes. The gravest consequences of atherosclerosis of the aorto-cranial vasculature is, therefore, not in the diminution of blood-carrying capacity but in the thrombotic lesions which they cause. The liability to thrombotic lesion-in presence of atherosclerosis-may well be subject to individual variations. This conclusion is perhaps supported by a study of atherosclerosis in a variety of animals. Despite the high incidence of this condition in animals, 'there was a surprising paucity of athero-thrombosis in comparison with man' (Finlayson, Symonds and T-W-Fiennes, 1962).

The pathology of the occlusive process affecting the carotid arteries was reviewed by one of the authors in this journal (Behrman, 1954). The vertebral arteries, while subject to similar morbid processes, may in the elderly become occluded when the already atheromatous artery is greatly displaced by osteoarthritic bony protuberances of the cervical spine. Very exceptionally, any of the $\stackrel{0}{0}$ pre-Willisian arteries can become the seat of giant-cell arteritis.

\section{Factors Giving Rise to Intermittent Strokes}

As already mentioned, Naffziger had suggested a 'fall of blood pressure below the patient's optimum level' might account for these transient disturbances of cerebral circulation. An associated pathological narrowing of the arteries of the circle of Willis or of the pre- or post-Willisian arterial channels would be an essential prerequisite. The following case illustrates the occurrence of recurrent hemiparesis consequent upon a fall of blood pressure during high pyrexia.

Case 1.-A student of 22 who was operated upon by one of us (G.C.K.) in 1954 on account of subarachnoid hæmorrhage. Arteriography revealed an aneurysm of the anterior communicating artery with the right anterior cerebral in spasm. As an emergency measure the left common carotid was ligated. Later that night he developed a fall in blood pressure with transient aphasia and right hemiparesis which recovered completely. Subsequently he remained well but was treated for urinary obstruction due to a valve in the prostatic urethra. He has from time to time suffered from recurrent attacks of catheter fever and in each of these he has an episode of aphasia and hemiparesis which recovers when the fever abates. Presumably the efficiency of the circle of Willis is embarrassed by the aneurysm on the anterior communicating artery, and the obstruction of the left common carotid artery.

Grimson, Orgain, Rowe and Sieber (1952) have described a patient who was under treatment with hypotensive drugs, and they noted that hemiplegia developed whenever the blood pressure fell below a certain level. This would suggest that co-existing arterial stenosis reduced the blood flow to one hemisphere. Cases have been described in which correction of either anæmia or of increased blood viscosity due to polycythæmia resulted in the cessation of intermittent 'strokes' (Millikan, Siekert and Whisnant, r96oa and b).

These various cases of intermittent 'strokes', in which the nature of the immediate precipitating factors can be clearly established, are of considerable importance in furthering our knowledge of the possible underlying pathological mechanisms. It must, however, be admitted that in the vast majority of cases deliberate provocation of the 'strokes' by simple lowering of the systemic blood pressure is not possible, and no fall in blood pressure can as a rule be observed at the commencment of these attacks. Nevertheless, the association of 'strokes' with myocardial infarction (Cole and Sugarman, 1952), excessive dehydration and occult gastro-intestinal bleeding are sufficiently common to call for their consideration in the clinical investigation of 'strokes'. 
Extra-cranial Arterial Reconstructive

\section{Surgery}

If in the investigation of recurrent transient aphasia or hemiparesis an obstructed carotid artery is found, it is easy to consider that this is the sole cause of the patient's symptoms and the objective to which treatment should be directeda view which has given a false impetus to arterial surgery in recurrent transient cerebral palsies, for in fact, cerebral ischæmia is not produced by stenosis of a single vessel alone. Cases are known in which both carotids are thrombosed yet the cerebral circulation is fully maintained by the veftebral and basilar systems. Vertebral thrombosis occurring in association with cervical spondylosis may be quite symptomless despite the distortion of vessels which occurs during movements of the neck, which may also twist the carotid branches at the bifurcation. It is not until both vertebral vessels are seriously involved that symptoms of basilar ischæmia are produced. For circulatory insufficiency to arise in association with a segmental stenosis in one artery there must be other factors at work, and perhaps more than one factor which will lead to impairment of the multiple pathways by which the blood supply to the brain is normally assured. Provided that the circle of Willis is patent and provided that the state of the aortic branches and the cardiac function are satisfactory, blockage of the carotid will not produce symptoms, indeed, when cerebral arteriography is performed after the carotid on the opposite side is compressed, the contrast medium flows readily to fill the contralateral hemisphere showing how easily nutrition can be maintained after carotid obstruction in normal circumstances.

There is a clear indication for surgery in the unilateral segmental lesion in a young subject without generalized arterial or cardiac disease. Even in these cases there must undoubtedly be a second factor, in that the cross-circulation through the circle must be ineffectual, but the indications for operation are clear-cut. There must be a partial obstruction of a short segment which usually has an audible bruit, often very highpitched, over the affected area and no evidence of generalized or progressive disease elsewhere. In such cases thrombectomy is the operation of choice. The artery is opened, the obstruction removed and the artery resutured. This is a small procedure which can be rapidly completed and the results are generally good. Excision and resuture of a segment is less likely to be successful. For either method to succeed operation must be performed early, before long-standing ischæmia or complete obstruction has produced an irreversible change. Surgery, and indeed arterial investigations, should never be employed when the ischæmic episode arises late in an established syndrome which has already given evidence of a progressive course, and probably investigation is best avoided in the absence of an audible bruit. The following two cases illustrate the complexities of this problem.

Case 2.-A man of 68 , a sufferer from chronic bronchitis since the r914 war, who developed coronary thrombosis in November r96r. On examination he was breathless at rest, his lips slightly cyanotic, his apex beat $\frac{1}{2}$ inch to the left, blood pressure $160 / 90 \mathrm{~mm}$. $\mathrm{Hg}$. Pulsation in the left brachial and radial arteries much reduced. The fundi showed marked narrowing of the arteries and nipping of the veins. Since 1959 he had had recurrent attacks of weakness in the left arm and leg and loss of central vision in the right eye, which persisted for about 5 minutes on each occasion before normal compensatory mechanisms were brought into play and terminated the attacks. Angiography revealed two areas of constriction of the internal carotid, but despite this the cerebral vessels were well filled; obviously there could be no indication for intervention.

Case 3.-This illustrates the danger of the increasing thrombotic lesion. This was a high-powered alert business tycoon who developed an attack of confusion whilst crossing the road, as a result of which he was knocked down by a cyclist. He was admitted to hospital with severe symptoms including right hemiparesis and aphasia but recovered rapidly within a week, which he would not have done had these symptoms been due entirely to associated head injury. He returned home, with normal speech and movement, but became severelye exhausted at the end of a tiring visit from many relatives and became confused and aphasic with recurrent mild paresis, thus illustrating the effect of fatigue in these cases. His doctors decided to investigate him for carotid artery thrombosis. Arteriography was performed-with disastrous results. He recovered from the anæsthetic but with complete paralysis, was totally aphasic and had frequent recurrent epileptic fits and some mental impairment. As years have passed his power of movement and speech have improved to some extent but his mental faculties and memory have deteriorated even further and he is developing Parkinsonian features and a Parkinsonian posture of the hand from the steady progression of his arterial degeneration, which probably showed its first symptoms immediately prior to his accident.

The published cases which have been treated with reconstructive surgery fall into two main groups:

(I) Cases in which the operation has been performed as a prophylactic procedure, to prevent further strokes. In the assessment of the value of reconstructive arterial surgery in this group of intermittent strokes we are handicapped by our lack of knowledge of the natural history of such cases.

(2) Cases with irreversible cerebral damage. As is to be expected, no significant change was noted in these cases following surgery (Rob, r960; De Bakey, Crawford and Fields, 196r). 


\section{'Strokes' Due to Spasm of Cranial Arteries}

We come now to the effects of ischæmia accompanying spasm of the arteries. It is well known that branches of the circle of Willis are liable to pass into spasm when irritated by the blood effused in subarachnoid hæmorrhage. It is probably less well known that a relatively small subarachnoid can by this mechanism produce an extensive cerebral infarction, sufficient to kill the patient.

Case 4.-A recent case admitted to the British Postgraduate Medical School under the care of one of us (G.C.K.) was that of an office-cleaner who had developed subarachnoid hæmorrhage at 6 o'clock in the morning. On admission to the hospital at 7.30 a.m. she was restless with increasing signs of brain stem failure, cessation of respiration occurring within three hours of the first hæmorrhage. Arteriography performed on artificial respiration showed that there was complete obliteration of both carotids above the level of the cavernous sinus by spasm and presumably this spasm was widespread and the cause of brain stem failure, for at post-mortem only a relatively small subarachnoid hæmorrhage was found.

Case 5.-A man, aged 37, was admitted elsewhere for investigation of a splitting headache and pain behind the right eye associated with vomiting and slowing of the pulse. These symptoms subsided spontaneously, but ten days later he again suffered a sudden change, with headache, vomiting, slow pulse and loss of consciousness; leucocytosis and a high ESR were demonstrated, and he was transferred for investigation. Examination revealed left-sided hemiparesis, astereognosis and hemianopia, and early papillœdema. Rightparietal biopsy revealed only soft brain into which the needle dropped like a plummet. A malignant glioma was suspected and nothing further was done. The following day his condition deteriorated with a pulse rate down to 40 . Although biopsy had not revealed a tumour it was decided that urgent exploration was indicated. It was found that the posterior portion of the right parietal and temporal lobes were grossly swollen and softened. Sufficient of the non-essential portions of this area was removed to relieve urgent pressure, following which the dura could be easily sutured. The patient was considerably improved, but examination of the tissue removed showed only cerebral œdema with softening. The patient has recovered and leads a useful life with a minimal hemiparesis and occasional epileptic attacks. An arteriography performed later revealed a small aneurysm on the posterior communicating artery with marked vasospasm.

In face of such clinical evidence, neither the reality nor the magnitude of spasm of preWillisian arteries can be disputed. The contraction of these arteries can give rise to 'strokes' albeit under special circumstances, even when these arteries are free from occlusive disease. Given a degree of stenosis by virtue of structural disease, it could be assumed that on occasions a physiologically induced contraction of these arteries might lead to a remitting or permanent stroke. As was already mentioned, classical remitting strokes, in individuals subject to them, cannot be precipitated by lowering the systemic blood pressure. Some other agency must, therefore, be invoked. The work of Seymour S. Kety (196I) in recent years on the cerebral circulation led to a drastic revision of long-held concepts that cerebral blood flow followed passively and irrevocably the corresponding changes in blood pressure.

\section{Strokes Due to Migraine}

Infarction with permanent damage of tissue resulting from vasospasm is also encountered in certain cases of severe hemiplegic migraine.

Case 6.-A patient of 33 had for some years suffered from right and left hemicrania with teichopsia. While walking down a street in a severe attack of migraine, she suddenly felt the right half of her body paralyzed and could not see the right half of the street. There was no loss of consciousness and no pain in the neck, yet on admission elsewhere she was investigated as a suspected case of subarachnoid hæmorrhage with negative results. Her right hemiparesis and hemianæsthesia resolved in the course of some weeks, but she was left with persistent quadrantic hemianopia.

Recent review of a series of cases of cervical sympathectomy performed in 1954 for the treatment of migraine has shown that patients who exhibited marked evidence of ischæmia such as paræsthesia, weakness or oculomotor paresis dur? ing the vasospastic stage of the migraine attack may be completely relieved of these symptoms by? cervical sympathectomy (Knight, 1962). There therefore appears to be a strong indication for the employment of this form of treatment as a protective measure to prevent persistent sequelæ developing from infarction in cases where ischæmic phenomena are severe.

\section{'Strokes' Due to Cerebral Gliomas}

Many gliomas infiltrate between the nervefibre tracts which at first continue to function and conduct between the tumour cells; however, the blood supply of the white matter is so tenuous that it cannot support indefinitely the circulatory demands of the growth. Eventually the tumour outgrows its blood supply with resulting infarction and necrosis of the centre portions of the growth. Since fibres can no longer conduct by this route symptoms suddenly appear like a vascular syndrome in a subject who may not exhibit evidence of arterial disease. Initial symptoms of contralateral weakness, confusion and headache may improve quite appreciably after the onset, again mimicking the vascular lesion, to be followed at an interval by a progressive course and papillœdema characteristic of a space-occupying lesion. Very rarely the bleeding from a glioma may escape into the subarachnoid space, when the 
clinical picture will assume the features of a subarachnoid hæmorrhage (Glass and Abbott, 1955).

\section{'Progressive Strokes'}

Occasionally the apoplectic onset of disturbance of neurological function is lacking, and symptoms appear gradually in the course of occlusive cerebrovascular disease. This may occur when repeated separation of small emboli from the wall of an aneurysmal sac or mural thrombus leads to repeated plugging of end-vessels producing a progressive paralytic syndrome simulating a cerebral neoplasm. Differentiation is occasionally possible when it can be established that progression occurred in step-like fashion.

The following case illustrates the more continuous, tardy development of paralysis caused by occlusion of right carotid artery.

\section{Case 7.-Man, aged $6 \mathrm{I}$.}

7.7.196r: First began to complain of pain around the right eye.

19.8.6r: Epileptic seizure.

2.9.6r: 'Could not see properly with the right eye for some minutes on awakening in the morning'.

20.9.6 1 : Became 'strange' in his behaviour, and began to have difficulty in using the left hand. Complaining of tingling and loss of sensation in the left hand, and around lips and tongue. Paralysis of the left limbs increased gradually during the following eight days.

In a recently published series of 153 carotid artery occlusions, symptoms commenced in seven patients with some minor neurological deficit which gradually increased without remission. Eventually a complete hemiplegia developed after an interval ranging from five days to 14 months (Hardy, Linder, Thomas and Gurdjian, 1962). If added to this clinical picture are symptoms such as headaches, seizures and oculomotor palsies, it will be realized that the differential diagnosis from intracranial tumours may present great difficulties. It is exceptional for 'strokes' to give rise to clinical manifestations of raised intracranial pressure as in Case 5 .

\section{Collateral Circulation}

An anastomosis between the branches of internal maxillary branch of the external carotid artery and the ophthalmic branch of the internal carotid, is one of the better known collateral channels connecting the internal and external carotid arteries. Carotid angiography has established the paramount importance of these collateral channels in cases of occlusion of the internal carotid artery. The degree of development of these channels is subject to considerable variation. $A$ priori it must be assumed that the development of these compensatory channels requires time, and can only become adequate if the occlusion of the carotid has appeared gradually.

\section{Angiography}

The great diagnostic value of angiography of the cranial arteries may perhaps tend to mask the hazards this procedure entails. With increasing improvement in technique and skill of the operators, the incidence of complications has been diminishing steadily, but tragic results such as occurred in Case 3, though rare, must always be borne in mind. There remains, however, a group of cases in which the incidence of complications still remains relatively high. This group comprises cases in which one or more cranial arteries are in spasm, especially after a subarachnoid hæmorrhage.

The influence of angiography upon pre-existing arterial spasm is well illustrated by some experiments described by Raynor and Ross (1960). The exposed carotid artery of cats under pentothal was stroked by a blunt instrument some 20 times for a distance of $1 \mathrm{~cm}$. By a photographic technique it was possible to measure the extent and duration of the arterial spasm so produced. When contrast medium was injected immediately after stroking, while the artery was in spasm, the duration of the spasm was prolonged about fivefold.

\section{Summary}

I. The ischæmic stroke is defined as disturbance of neurological function resulting from cerebrovascular occlusion.

2. A variety of ischæmic strokes are considered, viz.: intermittent strokes, strokes due to spasm of cranial arteries, strokes due to migraine, strokes due to cerebral gliomas and 'progressive' strokes.

3. The limited scope of extra-cranial arterial reconstructive surgery is emphasized.

4. It is stressed that after the age of 50 the incidence is high of widespread narrowing of the arteries conveying blood to the brain.

5. This narrowing, whether associated with occlusion or not, is often symptomless. The diminution of blood carrying capacity of these vessels is therefore relatively unimportant.

6. The gravest consequence of this pathological process is due to consequent athero-thrombosis.

7. Given a degree of atherosclerosis, the liability to athero-thrombosis may be subject to individual variation. A recent study of atherosclerosis in a variety of animals revealed that 'there was a surprising paucity of atherothrombosis in comparison with man'. 


\section{REFERENCES}

BAKER, A. B., and IANnone, A. (196I): Cerebrovascular Disease, vii, Neurology (Minneap.), 2, 23.

Behrman, S. (1954): Thrombosis of the Internal Carotid Artery, Postgrad. med. Y., 30, 570.

Cole, S. L., and Sugarman, J. N. (1952): Cerebral Manifestations of Acute Myocardial Infarction, Amer. F. med. Sci., 223, 35 .

De Bakey, M. E., Crawford, E. S., and Fields, S. W. (196r): Surgical Treatment of Patients with Cerebral Arterial Insufficiency Associated with Extracranial Arterial Occlusive Lesions, Neurology (Minneap.), 2, 145.

Fazekas, J. F., YaAn, R. H., Gallow, A. D., Paul, R. E., and Alman, R. W. (r962): Studies of Cerebral Hæmodynamics in Aortocranial Disease, New Engl. F. Med., 266, 224.

Finlayson, R., Symonds, C., and Fiennes, T- W- (1962): Atherosclerosis-a Comparative Study, Brit. med. $\mathscr{F}$., i, 501.

Fleming, H. W., and Naffziger, H. C. (1927): Physiology and Treatment of Transient Hemiplegia, $\mathcal{F}$. Amer. med. Ass., 89, 1484 .

Glass, B., and Аввотт, K. H. (r955): Subarachnoid Hemorrhage Consequent to Intracranial Tumours, Arch. Neurol. Psychiat. (Chicago), 73, 369.

Graves, R. J. (1884): 'Clinical Lectures on the Practice of Medicine'. New Sydenham Society.

Grimson, K. S., Orgain, E. S., Rowe, C. R., and Sieber, H. A. (1952): Caution with Regard to Use of Hexamethonium, F. Amer. med. Ass., 149, 215.

Hardy, W. G., Linder, D. W., Thomas, L. M., and Gurdjian, E. S. (1962): Anticipated Clinical Course in Carotid Artery Occlusion, Arch. Neurol. (Chicago), 6, 138.

Hicks, S. P., and WARREN, S. (I95I): Infarction of the Brain without Thrombosis, Arch. Path., 52, 403.

KeTtY, S. S. (196I): Internations Conference on Vascular Disease of Brain, Neurology (Minneap.), $2,72$.

Knight, G. C. (1962): 'Surgical Treatment of Migraine', Proc. roy. Soc. Med. (in press).

Martin, M. J., Whisnant, J. P., and Sayre, G. P. (1960): Occlusive Vascular Disease in the Extra-cranial Cerebral Circulation, Arch. Neurol. (Chicago), 3, 530.

Millikan, H. C., Siekert, R. G., and Whisnant, J. P. (1960a): Occlusive Disease in the Carotid Arterial System, Int. $\mathcal{Y}$. Neurol., $\mathrm{r}, 223$.

- , - (1960b): Intermittent Carotid and Vestebro-basilar Insufficiency Associated with Polycythemia, Neuology (Minneap.), ro, 188.

Osler, W. (I9I I): Transient Attacks of Aphasia and Paralyses in States of High Blood Pressure and Arteriosclerosis, Canad. med. Ass. F., i, 919.

Raynor, R. B., and Ross, L. (1960): Arteriography and Vasospasm: The Effects of Intracarotid Contrast Media on Vasospasm, $\mathcal{F}$. Neurosurg., 17, 1055 .

Roв, C. G. (1960): 'Pathogenesis and Treatment of Occlusive Arterial Disease'. Ed. by L. McDonald, p. 85. London: Pitman.

Russell, W. (1909): Intermittent Closing of Cerebral Arteries, Brit. med. J., ii, r 109.

Yates, P. O., and Hutchinson, E. C. (1961): Cerebral Infarction, Spec. Rep. Ser. med. Res. Coun. (London), No. 300. 